\title{
The role of Action Learning in supporting cross-cultural adaptation of international students
}

\author{
Helen Collins - Liverpool John Moores University \\ David Callaghan - Liverpool School of Tropical Medicine
}

Helen Collins is a lecturer in Liverpool Business School at Liverpool John Moores University. She is Programme Leader for a Masters in International Human Resource Management and has a special interest in the pastoral care of international students and internationalisation of the curriculum.

David Callaghan is a Senior Education Technologist at the Liverpool School of Tropical Medicine, researching effective use of learning technologies and supporting delivery to students. He has a particular interest in using technology to amplify the voices of participants (tutors and students) via online discussion forums and peer review. He tweets at @dbcallaghan and @LSTMTEL.

\section{Abstract}

We explore the reflections of a lecturer using Action Learning $(A L)$ meetings for the dissertation module on a one-year Master's programme with a predominantly international student cohort. We focus on two concerns: to what extent does AL mitigate against the negative experiences of crosscultural adaptation? And can we surface and share the learning that occurs when (international) scholars become practitioners and practitioners become (international) scholars? In the AL groups, many students seem more at ease with themselves, others and content in AL meetings than in other sessions. We scrutinised $A L$ and our $A L$ meetings to explore what makes it different and perhaps a better learning experience for the international student. This paper emerged following discussions with David, an e-learning and pedagogic specialist. Before continuing, note that there are two terms discussed in the literature: 'cross-cultural adjustment' and 'cross cultural adaptation'. 'Adjustment' refers to minor changes to cope with when facing a new situation, 'adaptation' to larger scale changes [Haslberger, Arno, and Chris Brewster. 2007. "Domains of Expatriate Adjustment with Special Emphasis on Work." Presented at the Cadiz University's VI International Workshop on Human Resource Management, Jerez, Spain]. We suggest that AL be used more often and earlier with international students.

KEYWORDS: Action Learning, international students, cross-cultural adjustment, cross-cultural adaptation 


\section{Introduction}

Whilst Action Learning (AL) has been a feature of human resource development practice for over half a century, and is practised by scholars and practitioners globally, the focus has often been on exploring accounts of practice, typically in case study form. Less focus has been on exploring the impact of $A L$ beyond its intended reach, in this case to international students adapting to a new culture. Consideration of these debates can help us shed light on the potential AL has for making a broader contribution to international student experience. On the surface it seems that the problems created during cross-cultural adaptation can be resolved in part by AL.

For many students, the style and method of teaching and learning in their host country differs significantly from their previous experience. The use of $A L$ in this context with its demands on student participation and de-emphasis of an expert role could be seen to increase the demands on international students who are already challenged by cross-cultural adjustment issues. However, what we have found is that AL assists students with cross-cultural adaptation, and suggest that AL may be an effective means of providing an environment that supports the diverse cultural needs of international students. AL was selected for the dissertation stage of the programme for three reasons. First, the University has a tradition of AL on Masters' programmes thus we were following a tried and tested format. Second, with large student numbers on dissertation modules at any one time, dividing students into groups of eight within AL groups enables the module to be managed well. Third, AL is seen to provide a mechanism for addressing real-life business issues whilst developing leadership and management skills and as such is a perfect fit for our aspiring HRM practitioners.

The paper is structured as follows: the first section addresses international education and its benefits, both to individuals and wider society. The second considers the problems faced by international students. Third, we detail our rationale and approach using AL and how we thought that would benefit the cohort. Fourth, we discuss the unanticipated benefit - the main driver for this paper - suggesting a symbiotic relationship between AL and cross-cultural adaptation, and some of the issues that may arise using AL with international students. Finally, we make some suggestions for the HE sector and areas for the AL community to consider for future research.

\section{International education and the benefits to individuals and society.}

Research into issues of international student cross-cultural adjustment was stimulated by the post second world war boom in student exchanges. At the same time two new concepts were developed. First was the $U$ curve of cultural adjustment (Lysgaard 1955); the second was the notion of culture shock (Oberg 1960), that as the name suggests embodies the belief that entering a new culture is potentially a disorienting experience.

As a student's cross-cultural understanding increases, it can transform the student into a human bridge, enabling them to become mediators between cultures (Adler 1975; Kim \& Gudykunst 1988). Indeed Bochner (1986) credits international education as a positive influence on world relations. Likewise, the transformative potential of Action Learning also has societal impact. Revans states that $L=P+Q$ i.e. Learning is Programmed Knowledge plus Questioning insight. Revans $(1984,16)$ explains:

$P$ is the concern of the traditional academy; $Q$ is the field of action learning... on the whole, however, programmed knowledge, $P$, already set out in books or known by expert authorities, is quite insufficient for keeping on top of a world like ours today, racked by 
change of every kind. Programmed knowledge must not only be expanded: it must be supplemented by questioning insight, the capacity to identify useful and fresh lines of enquiry. This we may denote by $Q$, so that learning means not only supplementing $P$ but developing $Q$ as well. It is arguable which is more important in 1984; the evidence is that a surfeit of $P$ inhibits $Q$, and that experts, loaded with $P$, are the greatest menace to adaptation to change by questioning $Q$.

We suggest that Revans' words, written over 30 years ago, ring very true for international students today. Having already had their world views shifted or adjusted throughout induction and earlier modules, students arrive in the AL group with both fewer certainties, or $\mathrm{P}$, and greater capacity to challenge, or $Q$, thus more predisposed for the $L$ that unfolds.

\section{Problems faced by international students}

Cross-cultural adaptation refers to how students cope with cultural changes; for the adaptation to be successful, several uncertainties have to be overcome (Kim 2001). While universities might be anxious for the new student to 'master the new environment' quickly, Ying and Liese (1991) sound a cautionary note and state that we should be extremely mindful of the students' emotional wellbeing during the adaptation process. With increasing access to the internet, socialising through online groups is more possible and gives international students a way of communicating with others, and is an important part of their social networking. Further, technology can afford a continuity of AL through Virtual Action Learning; as evidenced in an earlier dissertation cohort where one student said:

"...the webinar made it a concrete tangible process which brought about a change in my state of mind that yes I was on the right track, yes other people were feeling the same way and yes there was somebody there (David) to reaffirm I wasn't going mad".

Corcoran $(2015,1)$

As well as a new culture to contend with, international students often encounter pedagogical and curricular adjustment difficulties due to teaching methods that may be different from those they are accustomed to in their home cultures. International students sometimes perceive the content of the curriculum as exclusionary and cite concerns that instructors show a lack of interest in their prior knowledge (Arthur 2004). As we will see below, AL, with its focus on questioning insight, might be said to privilege prior knowledge compared to other forms of learning.

\section{Action Learning}

Our understanding of AL is a 'problem exploration process' that will develop students' question forming, coaching, and reflective skills. Revans' original design was aimed at organisation development, whereas we concentrate on the problem of the production of a dissertation as evidence of personal development - although in developing the individual, one inevitably develops their organisation.

Revans' 1945 learning approach, designed for the Coal Board, wasn't immediately implemented. But for three years around 1950, small groups of coal mine managers met to discuss each other's problems and coach colleagues to explore solutions, following the initial learning design. The managers discovered what sort of questions to ask when "facing 'wicked' or unpredictable problems without easy, or indeed any, answer" (Brook, Pedler and Burgoyne 2012, 271). 
Reflecting on what I did, we see parallels between the coal managers of the 1950s and the students at the dissertation stage of an academic programme. The problems of how to shore up a mine, work foreign machinery, replace ancient transportation systems seem akin to a myriad of dissertation topics. Revans' design of bringing together individuals with a major piece of work to do (problems with no 'right answers' (Brook, Pedler and Burgoyne 2012, 271)), to discuss and explore the issues with each other (questioning), to develop solutions (knowledge) where there may be a significant penalty for failure (Revans 2011), seems equally applicable to 2018 dissertation students as it did to 1950s coal mine managers. It's the "... same simple idea - that those with responsible jobs to do, whether managers or not, learn best with and from each other when systematically brought together during the doing of those jobs..." (Revans 1982, 74).

There are parallels between AL and social constructivist pedagogies. Social Constructivism (SC) holds that knowledge is built inside individuals through social interaction. Amid critique of SC pedagogies, a suggestion that institutions have over-zealously adopted approaches variously named "discovery learning, problem-based learning, inquiry learning, experiential learning, and constructivist learning" (Kirschner, Sweller and Clark 2006, 75), concluded that after 50 years of experimentation there is no evidence to support SC approaches, and suggested a "Sage on the Stage" approach (King 1993, 30) is more effective. Although we accept this may be true for novice learners, we feel that for expert practitioners with 'wicked' problems where "... no one knows the solution to the problem, and no one knows the way out of a complex situation" (Zuber-Skerritt 1993, 46), AL is the most effective pedagogy.

Further, I was encouraged in my use of an AL approach as David had positive experience using elements of the AL pedagogy with a dissertation group; elements such as questioning, feedback, and a group mentality (Callaghan, 2013; Corcoran 2015) that led 57\% of the cohort to receive 'First' in the module (Callaghan, 2013).

\section{Methodology}

As this did not set out to be a piece of research, there was no planned methodology. However, methods included keeping personal diaries and observation. Analysis included narrative inquiry (Duff and Bell 2002) - as detailed below.

\section{What I did}

Students were made aware right at the start of their Masters programme that the dissertation phase is managed through Action Learning. For many it is the first time they have heard of AL or engaged in it. For most, buy-in was straightforward but for some a challenge arose when seeking to promote $A L$ to international students who, bought in to the AL ethos, but were keen to have prior knowledge about method and outcomes. In this sense, AL might be viewed as a conflicting philosophy, with a focus which is very much on the journey, rather than the destination. For some international students, added stressors over visa and completion regulations might make the necessary prevarications of the AL meetings seem frivolous.

The module comprised multiple sets of eight to ten members. My group of eight members (nine including me, and I attended all meetings) met seven times over a five month period. At the first meeting we established group etiquette through each person talking for five minutes about their expectations and dissertation plans. Each member then invited others to question and in so doing some plans and expectations were reframed. I facilitated the first group, and a different student member facilitated at each subsequent meeting. In between AL meetings work was exchanged on 
line for peer comments and questions raised and responses posted on our on line discussion group. After initial reluctance by some to participate, by the second AL meeting everyone was joining in and working alongside each other co-developing ideas. Whilst my formal role as facilitator only lasted for the first group, I felt inclined to be a co-facilitator for the whole AL journey, and felt it was incumbent upon me to meet the diverse needs of a multicultural student group and to encourage everyone to actively participate in the learning.

At the first AL meeting we agreed to use diaries to write up our actions and reflections after and in between AL meetings. About half the group started a diary after the first AL meeting; more were inspired to do so when they could see the benefit others derived in seeing in print just how far their conceptual thinking had shifted between diary entries.

During the first meeting (four hours) members encouraged shared reflexivity as a means of eliciting initially opaque meanings, and of exploring new openings and connections. As the AL meetings met again, members identified new questions and ways of sharing and responding. At the first meeting, I facilitated and invited each member to share their aims, literature they planned to review, how they planned to get primary research and generally what their aspirations were for the dissertation journey.

\section{Analysis}

This account emerged from a first-hand experience of being in a series of AL meetings over several months with international students, and is motivated by the ambition to understand in a more systematic way how international students cope with the experience of learning in a foreign country. Through conversations and questions in meetings, on line discussion outside of meetings and (some) diary sharing, rather than traditional interviewing, I assumed that thoughts on participants' experiences as international students might not be readily available in their minds. Students might find it difficult to provide insights about aspects that they might never have reflected upon. In hindsight, my methodological choice was guided precisely by the intention to give participants the opportunity to reflect upon their own trajectories, and reach new understandings of their experience through AL meetings. Hence, it might be said that a very loose and informal narrative inquiry was used that allowed me to 'get at information that people do not consciously know about themselves' (Duff and Bell 2002, 209). Rather than any formal data collection, I felt the need to stimulate students' reflexivity and to construct meaning through our interaction.

In regard to the actual modus operandi of this narrative inquiry, at the first meeting each student was asked to recount his/her experience of the issue their dissertation would address. Before the next meeting work was shared on line, and peer comments and questions were raised. At the second and subsequent meetings, members questioned and sometimes reframed their thinking as a result of interaction and reflection, so in contrast to a traditional process of data collection, the eight members were involved in the actual co-construction of the data.

\section{Findings}

As there was no initial methodology our findings are very dependent on remembered observations, scribbled quotes in diaries and later reflections.

Having taught the same cohort of international students in previous modules using more traditional teaching and learning methods, I was gratified to notice significantly higher student engagement in the AL meetings, and as one member said: 
“... I just enjoy the AL meetings so much ... and feel more involved, we get to communicate much much more than usual ...".

Initially this was perceived as an increase in the noise level that, on further observation, was seen to be increased engagement by all members of the cohort. I was further encouraged to pursue the approach as participation by all members aligned with my philosophy of equality and respect for different opinions and perspectives. Another member said:

"so much theory doesn't really fit back at home and the AL meetings are the place we can debate theories without feeling dumb".

I found it easier to engage students in the dissertation module with its AL approach, than in modules with more traditional teaching methods, and we suggest several factors that may be at play here. First, the AL pedagogy requires listening to others' opinions and experience, thus all students were expected to contribute - it was more difficult for someone to 'take a back seat'. Second, the largely international cohort may have less pre-conceptions of topic presented and thus more willing to contribute. Third, having a multicultural cohort led to an unusually large number of differing perspectives and opinions in each AL meeting, making it easier to tease out alternative perspectives on issues - the idea of thinking 'outside of the box' was 'inside of the room'.

However, the main driver for this paper was the unexpected outcome - how the AL approach seemed to fit so well with addressing international students' cross-cultural issues. International students face problems of loneliness, lack of meaningful relationships, low social support, academic stress, isolation and culture shock. Rather unexpectedly, we found that AL's key principles effectively address such issues.

For example, the AL principles of Group work, Inclusivity, Listening, and Equality led to students feeling less isolated and gaining social support. For one participant the AL group made them feel '...Just being with others made the learning more real...', yet another felt more included '... I only started to feel part of the course when the AL meetings started....'. It is acknowledged that listening for sustained periods of time when the language spoken in the group is not your first language can be very difficult; for at least one of our group, AL meetings really helped to develop their listening skills '... having to ask and answer questions makes me a much better listener than in other groups...'.

It is unfortunate that equality in teaching and learning is not widely experienced by international students, with suggestions that prior experience, cultural and pedagogic differences are sometimes discounted or unexplored. Within the AL group, some of these concerns disappeared '.... it just feels like we all count in the AL meetings, what we ask and say matters and we are treated equally, including with the facilitator....'

The principles of foregrounding student experience and emphasis on new perspectives strengthened students' academic confidence and encouraged them to use their background and experience to give unique insights on issues that groups were discussing: '......Because I was talking about real problems in my country and had to answer questions from the group, I felt much more confident in my academic skills after the AL meetings....' And from another '....Everyone's culture is different, the AL group was the only time in my course when I felt able to talk about my culture....' 


\section{Discussion and conclusion}

\section{Is the relationship between Action Learning and cross-cultural adaption straightforward?}

The demands of the one-year Masters course pose an enormous challenge to some students. The need to adapt to new styles of learning such as AL may prove onerous for international students whose cultural background emphasises passive learning and respect for authority, not tolerating challenging or questioning the teacher.

AL encourages one to question taken for granted beliefs and theories - which can make a student, as Lawless $(2008,127)$ points out, 'begin to feel isolated from his or her community'. In this sense, and already isolated from their home communities, their already fragile sense of belonging to their host community, might become yet more fragile. Further, it is important that in attempting to ameliorate problems of cross-cultural adaptation through AL, we must not single out international students since this may result in further isolation.

AL's use of assumption breaking and insightful questioning might be perceived as a luxury afforded to academics and not practitioners in the commercial world. Excessive questioning can be burdensome, leading to delays and indecisiveness and can be exacerbated when the language of the group is not your first language.

Notwithstanding these difficulties, getting the balance right to create $A L$ that encourages action and learning can be achieved by skilled facilitation. A facilitator helps members to accept uncertainty, as no right or final answer exists, and understand the conscious and unconscious interests influencing the question. The facilitator can see opportunity in the challenges afforded by international students since an AL group comprised of international students is by nature diverse, and is not restricted by parochial concerns or localism. Questions can be more outlandish or hackneyed, creating strength out of an apparent position of weakness. Indeed as Revans $(1983,16)$ himself says:

... the essence of Action Learning is to pose increasingly insightful questions from an origin of ignorance, risk and confusion...'

To answer half of one of our questions, this provides the seedbed for surfacing the learning that occurs as international students prepare to become practitioners but does it enable practitioners to become scholars? We believe that by interrogating prior learning and experience, it goes some way towards this.

In this paper we have argued $A L$ as a potential remedy for alleviating the adjustment difficulties international students may face. Thinking about teaching and learning with international students raises some uncomfortable issues, not least that teaching method is typically reflective of the values, attitudes and beliefs of a particular culture and an institution that forces students to assimilate to an unfamiliar learning culture. We think AL, with its focus on social and peer support, both counters some of the problems associated with reproducing hegemony in our teaching as well as resolving some of the problems of cross-cultural adaptation for our international students. Therefore we suggest that it should be offered earlier in a programme of study and more often, and as a continuous learning and support part of the international student experience through virtual action learning, such as via web conferencing and online forums. 


\section{Areas for further research}

We acknowledge that our data and findings are subjective, based largely on practitioner reflection. Having stumbled across a possible synergy between AL and international students, our next step is to seek a more objective approach, taking a structured methodology for the next cohorts of predominantly international students. We also welcome collaboration from others with international cohorts to create a larger source of data and a larger researcher community looking at how AL may address issues arising for those studying abroad.

\section{References}

Adler, Peter S. 1975. 'The Transitional Experience: An Alternative View of Culture Shock.' Journal of Humanistic Psychology.

Arthur, Nancy. 2004. 'Enhancing Counseling Services for International Students'. In Counseling International Students, 103-27. Springer.

Bochner, Stephen. 1986. 'Coping with Unfamiliar Cultures: Adjustment or Culture Learning?' Australian Journal of Psychology 38 (3): 347-58.

Brook, Cheryl, Mike Pedler, and John Burgoyne. 2012. 'Some Debates and Challenges in the Literature on Action Learning: The State of the Art since Revans'. Human Resource Development International 15 (3): 269-82.

Callaghan, David B. 2013. 'Learning Edge; Edge Hill's Virtual Learning Environment'. A Tidal Wave of Discussion ... How Active Discussion Produced Outstanding Results. November 1. https://blogs.edgehill.ac.uk/learningedge/2013/11/01/a-tidal-wave-of-discussion/.

Corcoran, Lisa. 2015. 'Learning Edge; Edge Hill's Virtual Learning Environment'. Technologies Are an "Absolute Lifeline" for Our Students! January 27. https://blogs.edgehill.ac.uk/learningedge/2015/01/27/technologiesstudentlifeline/.

Duff, Patricia A, and Jill Sinclair Bell. 2002. 'Narrative Research in TESOL: Narrative Inquiry: More than Just Telling Stories'. TESOL Quarterly 36 (2): 207-13.

Haslberger, Arno, and Chris Brewster. 2007. 'Domains of Expatriate Adjustment with Special Emphasis on Work'. presented at the Cadiz University's VI. International Workshop on Human Resource Management, Jerez, Spain.

Kim, Young Yun, and William B Gudykunst. 1988. Cross-Cultural Adaptation: Current Approaches. Vol. 11. ERIC.

Kim, Young Yun. 2001. Becoming Intercultural: An Integrative Theory of Communication and CrossCultural Adaptation. Thousand Oaks, CA.: Sage.

King, Alison. 1993. 'From Sage on the Stage to Guide on the Side'. College Teaching 41 (1): 30-35.

Kirschner, Paul A, John Sweller, and Richard E Clark. 2006. 'Why Minimal Guidance during Instruction Does Not Work: An Analysis of the Failure of Constructivist, Discovery, Problem-Based, Experiential, and Inquiry-Based Teaching'. Educational Psychologist 41 (2): 75-86.

Lawless, Aileen. 2008. 'Action Learning as Legitimate Peripheral Participation'. Action Learning: Research and Practice 5 (2): 117-29. 
Lysgaard, Sverre. 1955. 'Adjustment in a Foreign Society: Norwegian Fulbright Grantees Visiting the United States. International Social Science Bulletin, 7, 45-51'. Journal of Counseling Psychology 53 (1): 126-31.

Oberg, Kalervo. 1960. 'Cultural Shock: Adjustment to New Cultural Environments'. Practical Anthropology 7 (4): 177-82.

Revans, Reginald W. 1982. 'What Is Action Learning?' Journal of Management Development 1 (3): 64-75. doi:10.1108/eb051529.

-- - 1983. ABC of Action Learning. 1st ed. Bromley, Kent: Chartwell-Bratt.

- - . 1984. The Sequence of Managerial Learning. Bradford: MCB University Press.

-- -. 2011. ABC of Action Learning. 1 edition. Routledge.

Ying, Yu-wen, and Lawrence H Liese. 1991. 'Emotional Well-Being of Taiwan Students in the US: An Examination of Pre-to Post-Arrival Differential'. International Journal of Intercultural Relations $15(3): 345-66$.

Zuber-Skerritt, Ortrun. 1993. 'Improving Learning and Teaching through Action Learning and Action Research'. Higher Education Research and Development 12 (1): 45-58. 